\title{
PPGLinC 10
}

\section{PROCESSOS E ESPAÇOS DE PARTICIPAÇÃO NA CULTURA ESCRITA NO SERTÃO BAIANO (SÉCULO XX)1}

\section{PROCESSES AND SPACES FOR PARTICIPATION IN THE WRITTEN CULTURE IN THE BAHIAN BACKLANDS (20th CENTURY)}

\section{Huda da Silva Santiago ${ }^{2}$ Universidade Estadual de Feira de Santana}

Resumo: O objetivo, neste trabalho, é discutir sobre indícios dos processos de difusão da escrita na zona rural do semiárido da Bahia, caracterizando práticas de letramento predominantes, principalmente, em meados do século XX. No campo da História Social da Cultura Escrita, buscase, pelas fontes orais, correlacionar os percursos de participação e apropriação nas/das práticas letradas ao desempenho de escrita de sertanejos que produziram cartas pessoais mesmo com o pouco acesso à escolarização formal. Além do espaço escolar, limitado, também os espaços domésticos, o acesso a alguns materiais de leitura e o processo de migração para grandes cidades propiciaram formas de participação nas práticas de letramento.

Palavras-Chave: História Social da Cultura Escrita; Sertão baiano; Espaços escolares e extraescolares.

1 Este estudo é parte dos resultados apresentados na tese de doutoramento A escrita por mãos inábeis: uma proposta de caracterização (2019), orientada pela professora Zenaide Carneiro e coorientada pelo professor Afrânio Barbosa. Alguns trechos deste texto, com os dados ainda preliminares, integram o capítulo O sistema educacional no semiárido baiano oitocentista e notas sobre a escolarização no período republicano feirense e da região sisaleira, de Carneiro, Almeida, Lacerda e Santiago (2020).

2 huda_santiago@uefs.br 
Abstract: This paper aims to discuss the evidence of the processes of dissemination of writing in the rural area of the semiarid region of Bahia, characterizing literacy practices, predominant, mainly, in the middle of the 20th century. In the field of Social History of Written Culture, it is sought, through oral sources, to correlate the paths of participation and appropriation in/from literate practices to the writing performance of sertanejos who drafted personal letters despite their little access to formal schooling. In addition to the school space, limited, the domestic spaces, access to some reading materials, and the migration process to large cities provided ways of participating in literacy practices.

Keywords: Social History of Written Culture; Bahian Backlands; School and outside school spaces.

\section{INTRODUÇÃO}

A partir de entrevistas-narrativas produzidas com alguns sertanejos, apresentam-se aspectos da difusão da escrita na zona rural do semiárido baiano, predominantes, principalmente, em meados do século XX, buscando-se, também, a partir das memórias, constituir seus perfis de letramento. A questão motivadora é: como ocorreu o processo de participação desses sertanejos na cultura escrita, apesar de muitos não terem frequentado o espaço escolar formal?

Correlacionam-se os percursos de participação e apropriação na/da cultura escrita ao desempenho de escrita dos sertanejos. As 131 cartas pessoais que integram o acervo Cartas em Sisal, do projeto Documentos produzidos por mãos inábeis: estudos linguísticos e filológicos (CONSEPE 083/2020), vinculado ao projeto Corpus Eletrônico de Documentos Históricos do Sertão (CE-DOHS), do Departamento de Letras e Artes, da Universidade Estadual de Feira de Santana (UEFS), são pistas de que, mesmo com a ausência ou precariedade das escolas e seu funcionamento irregular, na zona rural dos municípios de Riachão do Jacuípe, Conceição do Coité e Ichu, na época, alguns sertanejos aprenderam a escrever. No entanto, o pouco domínio da técnica, percebido nos manuscritos através dos aspectos caligráficos e ortográficos (SANTIAGO, 2019), indica que são redatores que tiveram pouco contato com os modelos prescritos pela escola. Como muitos dos remetentes e destinatários dessas cartas estão vivos, torna-se possível, 
através de suas memórias, uma aproximação aos seus processos de participação na cultura escrita.

No âmbito dos estudos linguísticos sócio-históricos, campo em que se insere a pesquisa que motivou este trabalho, quando não se trabalha com mãos mortas, a recorrência às fontes orais permite minimizar os desafios envolvidos na busca pela caracterização dos perfis sociais, no levantamento dos fatores externos à escrita. A construção da história da cultura escrita, que necessita de informações sobre quem escreveu e para que foi escrito o texto, pode contar com esse tipo de fontes, característico do novo fazer historiográfico (BURKE, 1992).

Durante o século XX, principalmente até a década de 1960 - período que corresponde à infância ou adolescência de boa parte dos redatores/destinatários das $\operatorname{cartas}^{3}$ - na zona rural da Bahia, o processo de criação e de funcionamento efetivo de escolas ainda ocorria com pouca frequência, mesmo que, nesse período, nas maiores cidades, comece a existir um crescimento da preocupação com a escolarização da população (SANTIAGO; CARNEIRO, 2016; SANTIAGO; LACERDA; CARNEIRO, 2019). Na zona rural, as poucas escolas que existiam funcionavam de modo precário, muitas vezes com professoras itinerantes, como atestam alguns estudos, como o de Cruz (2012), ao comprovar que, nesse período, a educação primária na zona rural da Bahia estava, em grande medida, nas mãos de leigos e, além disso, o número de escolas não correspondia às necessidades da população baiana em idade escolar.

Essa realidade não é muito diferente da situação do país, de modo geral. Segundo Galvão (2007), para a construção de uma história da cultura escrita no Brasil, é necessário considerar que o país, assim como outros de escolarização e imprensa tardias, até meados do século XX, foi marcado pela oralidade e pelo analfabetismo. Diante disso, algumas questões propostas por essa pesquisadora

3 Dos remetentes com data de nascimento identificada, a maior parte nasceu entre as décadas de 1920 e 1950. Quatro deles nasceram no século XIX. 
em relação ao geral do Brasil colaboram para a problematização, neste trabalho, do que ocorre no contexto rural baiano: i. "[...] de que maneira, numa sociedade marcada pelo analfabetismo, os indivíduos, as famílias e os grupos sociais distanciados, em maior ou menor grau, da cultura escrita, construíram modos de participação nessa cultura?", e ii. "Numa sociedade de parcimoniosa produção e circulação de impressos, por meio de que práticas esses sujeitos desenvolveram táticas de incursão numa cultura que não era, de origem, a sua?" (GALVÃO, 2007, p. 11-12).

Há estudos significativos referentes ao processo histórico de educação formal na Bahia, no âmbito das pesquisas na área de Educação, com foco, geralmente, na história da escola como instituição formal de educação, na perspectiva dos professores e nas políticas educacionais. São exemplos, os trabalhos reunidos por Souza e Cruz (2012), sobre as Escolas Normais na Bahia; a pesquisa de Carneiro (2014), sobre os percursos formativos das professoras leigas da região semiárida da Bahia, dos municípios de Riachão do Jacuípe, Ichu e Candeal, entre as décadas de 1950 e 1970, além do trabalho de Rios (2015), acerca da profissão docente na roça, em que analisa a trajetória de professores da região do Piemonte da Diamantina, interior da Bahia.

A ideia aqui, então, é deslocar o olhar: das instituições formais, para os espaços extrainstitucionais de aprendizagem; dos espaços urbanos, para os rurais; da história narrada por professores, para as memórias daqueles que vivenciaram os processos de letramento. Assume-se a perspectiva de uma história "vista de baixo", a corrente que explora as experiências históricas das pessoas comuns, “[...] daqueles homens e mulheres, cuja existência é tão frequentemente ignorada, tacitamente aceita ou mencionada apenas de passagem na principal corrente da história" (SHARPE, 1992, p. 41).

É com essa perspectiva, considerando a memória como um processo ativo de criação de sentidos (PORTELLI, 1991), que se fundamenta a tentativa de 
recuperar informações sobre práticas de escrita e processos de letramento dos sertanejos baianos, a partir de suas narrativas orais. O termo letramento é utilizado aqui em seu sentido mais amplo, associado à noção de letramento como prática social, segundo abordagem de Street (2014), assim como, de forma mais específica aos estudos da História Social da Cultura Escrita, aos eventos e práticas sociais mediados por material escrito, conforme Soares (2006).

Na próxima seção, comenta-se sobre o campo da História Social da Cultura Escrita, assim como sobre os aspectos metodológicos referentes ao diálogo com a História Oral, na produção de entrevistas-narrativas. Em seguida, discute-se sobre as práticas de letramento presentes no sertão baiano, no século XX: desde as experiências extraescolares, como o espaço doméstico; o processo de migração; o acesso a materiais impressos e a manuscritos, como os textos religiosos e os folhetos de cordéis; até a experiência escolar.

\section{SOBRE O CAMPO DA HISTÓRIA SOCIAL DA CULTURA ESCRITA}

Ao enfatizar o ponto de vista das pessoas comuns, dos anônimos, no âmbito da História Cultural, os estudos da História Social da Cultura Escrita propõem abordagens em torno das práticas cotidianas, que evidenciem as produções daqueles invisibilizados pela história oficial. Nesse sentido, a produção de narrativas do passado constitui-se como uma possibilidade de aproximação à memória coletiva que envolve as práticas de leitura e escrita do lugar, incluindo as práticas dos que não passaram pelo processo de alfabetização escolar. Segundo Castillo Gómez (2003), a História Social da Cultura Escrita busca estudar as práticas sociais de escrever e de ler, em um projeto que reconhece a escrita como algo mais que um mero sistema gráfico, questionando acerca das suas diferentes funções e práticas materiais, sempre em referência às respectivas sociedades históricas, “[...] tendo em conta que em cada momento a 
sociedade foi formada por alfabetizados e analfabetos"..4 (CASTILLO GÓMEZ, 2003, p. 96, tradução nossa).

Nessa mesma direção, Galvão $(2007,2010)$ afirma que, por meio da descrição minuciosa dos eventos e práticas sociais mediados por material escrito, é possível compreender o lugar que a escrita ocupa em determinada cultura. Uma possibilidade para conceituar "cultura escrita" seria, então, considerá-la como “[...] o lugar - simbólico e material - que o escrito ocupa em/para determinado grupo social, comunidade ou sociedade" (GALVÃO, 2010, p. 218). A autora propõe cinco vias, ou dimensões, para o estudo da cultura escrita em uma perspectiva histórica (GALVÃO, 2010, p. 221-223), sintetizadas a seguir:

i. a que se refere às instâncias ou instituições que ensinam ou possibilitam a circulação do escrito em certas épocas e em certos locais;

ii. fazer uma história dos objetos que lhe dão suporte;

iii. estudar os suportes por meio dos quais ela é difundida e ensinada;

iv. focalizar os sujeitos que, em suas vivências cotidianas, constroem historicamente os lugares simbólicos e materiais que o escrito ocupa nos grupos e nas sociedades que os constituem (e que, ao mesmo tempo, ajudam a constituir);

v. investigar os meios de produção e transmissão das múltiplas formas que o fenômeno assume.

Em relação às entrevistas-narrativas produzidas nesta pesquisa, os temas abordados pelos sujeitos perpassam algumas dessas vias, possibilitando identificar vestígios, principalmente, sobre o que trata a primeira via (além do espaço escolar, os espaços extraescolares) e, também, a segunda via (além do livro didático, os jornais, os cordéis, os calendários, os textos religiosos).

Chartier (2010) indica algumas modalidades da relação que as sociedades mantêm com o passado: o conhecimento produzido pelos historiadores, as obras de ficção e a memória, seja ela coletiva ou individual. Sem querer priorizar ou indicar a memória como superior, o autor lembra que uma das diferenças entre

4 "[...] teniendo em cuenta que em cada momento la sociedad ha estado formada por alfabetizados y analfabetos". (CASTILLO GÓMEZ, 2003, p. 96). 
história e memória é que "[...] à imediata fidelidade (ou suposta fidelidade) da memória opõe-se a intenção de verdade da história, baseada no processamento dos documentos, que são vestígios do passado, e nos modelos de inteligibilidade que constroem sua interpretação" (CHARTIER, 2010, p. 22). Opõe, assim, o reconhecimento do passado, exercido pela memória, à representação do passado, tencionada pelo discurso histórico. Para as comunidades em que a presença do passado no presente é um elemento essencial da construção do "ser coletivo", a memória é conduzida, ainda segundo o autor, por essas exigências existenciais.

Esse reconhecimento do passado, através da memória, auxilia na busca por respostas a algumas das questões indicadas por Petrucci (2003) na proposta do método de uma renovada paleografia, para aqueles que trabalham com testemunhos escritos, mais especificamente às seguintes questões:

Quem o realizou? A que ambiente sociocultural pertencia o executor e qual era em seu tempo e ambiente a difusão social da escrita.

Para que foi escrito esse texto? Qual era a finalidade específica desse testemunho em particular e, além disso, qual poderia ser em sua época e em seu lugar de produção a finalidade ideológica e social de escrever. (PETRUCCI, 2003, p. 7-8, tradução nossa). ${ }^{5}$

Auxiliando na busca por respostas a essas questões, as narrativas sobre o passado contribuem para o acesso a indícios do perfil sociocultural dos sertanejos e do contexto de produção dos manuscritos, fornecendo pistas acerca de seus processos de letramento. Esses processos ocorriam, muitas vezes, em dimensões não escolares, quando se inventava, cotidianamente, maneiras de fazer (CERTEAU, 2013), de se estabelecer práticas de escrita e leitura, seja na própria casa ou na de

\footnotetext{
5 “QQuién lo realizo? A qué ambiente sociocultural pertenecía el ejecutor y cuál era en su tiempo y ambiente la difusión social de la escritura. ¿Para qué fue escrito ese texto? Cuál era la finalidad específica de ese testimonio en particular y, además, cuál podia ser en su época y en su lugar de producción la finalidad ideológica y social de escribir." (PETRUCCI, 2003, p. 7-8). As demais questões do conjunto mínimo proposto por Petrucci (2003) são: $o$ quê? (em que consiste o texto escrito), quando e onde? (época e lugar da escrita) e como? (técnicas e materiais usados para a escrita).
} 
parentes, no convívio com amigos e/ou através do contato com outros materiais de leitura, como cartas, jornais e textos religiosos. A partir desses indícios, reconhecem-se a possibilidade e a necessidade de se produzir empoderamentos, de se legitimar as vozes daqueles que, ao longo do tempo, estiveram às margens das atividades de escrita, mas foram agentes, cujas ações afetaram o mundo (às vezes limitado) em que viviam, como lembra Sharpe (1992), referindo-se à história das pessoas comuns.

\subsection{A produção de entrevistas-narrativas: o recurso à História Oral}

Segundo Burke (1992), ao tratar das novas tendências do fazer historiográfico, a História Oral é um dos novos tipos de fonte que suplementam os documentos oficiais, desde que os historiadores começaram a fazer novos tipos de perguntas sobre o passado, escolhendo novos objetos de pesquisa.

A escolha pelas histórias de vida como meio para obtenção de indícios da difusão da escrita na zona rural do semiárido baiano, com o uso de entrevistasnarrativas ${ }^{6}$, baseia-se, portanto, nos pressupostos da História Oral, em uma atitude de dessujeição metodológica, como sugere Rodrigues (2010), ao justificar a opção pela pesquisa que força a sair da imobilidade de outras estratégias metodológicas, visando a uma dessujeição dos pesquisados e do pesquisador. Considera-se que as fontes históricas orais são fontes narrativas, no sentido proposto pelo historiador oral Portelli (1991). Para esse autor, a história oral é, primordialmente, uma arte da escuta, e, ao contrário da maioria dos documentos históricos, as fontes orais não são encontradas, mas cocriadas pelo historiador, caracterizadas como “[...] narrativas individuais, informais, dialógicas, criadas no encontro entre historiador e narrador" (PORTELLI, 2016, p. 9).

\footnotetext{
6 Essa expressão tem sido difundida pela Associação Brasileira de Pesquisa (Auto)Biográfica, ao usar entrevistas-narrativas como uma importante fonte de produção de dados, possibilitando interpretações acerca das trajetórias de vida (cf. SOUZA, 2015).
} 
Ao apresentar as especificidades da história oral, Portelli (1991) destaca como peculiaridades desse tipo de fonte a oralidade, a forma narrativa, a subjetividade, a credibilidade diferente da memória e a relação entre entrevistador e entrevistado. Sobre essa última peculiaridade, o autor afirma que o resultado final da entrevista é o produto de ambos, tanto do narrador como do pesquisador: "A comunicação sempre funciona de ambos os lados. [...] Os historiadores podem reconhecer esse fato e tirar dele vantagens, ao invés de tentar eliminá-lo em razão de uma neutralidade impossível (e talvez indesejável)" (PORTELLI, 1991, p. 54, tradução nossa)7 ${ }^{7}$ Um dos requisitos para a entrevista, então, é que o pesquisador aceite o informante e dê prioridade ao que ele deseja dizer, ainda que não seja o que o pesquisador quer ouvir, guardando quaisquer questões não respondidas para depois, como comenta Portelli (2016, p. 10), “[...] o que o historiador quer saber pode não necessariamente coincidir com o que o narrador quer contar".

É nesse mesmo sentido, no trabalho com fontes que são orais, narrativas e subjetivas, que cada entrevistado não deve ser entendido “[...] como uma mera fonte de 'informações' sobre o assunto, mas sim como uma pessoa que, de alguma maneira, vivenciou um pedaço de um momento histórico e se apropriou de forma pessoal de sua experiência", como também defende Worcman ${ }^{8}$ (2014, p. 151), que esclarece: “[...] o sucesso da entrevista depende muito da relação estabelecida entre entrevistado e entrevistador" e o roteiro é entendido apenas como um guia, um apoio (WORCMAN, 2014, p. 151).

Reconhecendo essa importância de uma relação aberta, atenciosa e acolhedora entre o pesquisador e o sujeito da pesquisa, que desencadeie uma

\footnotetext{
7 "Communications always work both ways. [...] Historians might as well recognize this fact and make the best of its advantages, rather than try to eliminate it for the sake of an impossible (and perhaps undesirable) neutrality." (PORTELLI, 1991, p. 54).

8 Fundadora do Instituto Museu da Pessoa, instituição virtual que desenvolve projetos a partir de uma metodologia que pressupõe ser a narrativa de cada pessoa a expressão de sua singularidade. Cf. www.museudapessoa.net.
} 
narrativa fluente, o mais livre e espontânea possível, o processo de produção das narrativas dos sertanejos contou com uma relação de proximidade entre entrevistado e entrevistador, por compartilharem uma mesma identidade local/geográfica; e, além disso, como foram feitas várias visitas na ocasião da constituição do acervo das cartas pessoais, as pessoas demonstraram estar bem à vontade no momento das gravações dos relatos, evidenciando receptividade e interesse pelas conversas.

O planejamento das entrevistas, com o estabelecimento de alguns temas previamente, teve a função apenas de fornecer apoio no desencadeamento da conversa, na provocação ao entrevistado em seu processo de evocação das memórias, já que no decorrer da narrativa surgiram outros assuntos ou alguns podem não ter sido mencionados. Considerando-se esse aspecto, foram escolhidos alguns temas, estabelecidos a partir do desejo de conhecer memórias/lembranças sobre as práticas de escrita e leitura constituídas no cotidiano dos sujeitos: a) a infância/juventude (onde viveu, aprendizados mais marcantes nesse período, relação com os pais); b) a oralidade (contação de histórias, tipos de histórias, quem contava); c) a aprendizagem da escrita (como se deu esse aprendizado, relação dos pais com a escrita, presença de professores/escolas na região, a produção das cartas), e d) a leitura (presença de materiais de leitura em casa, práticas de leitura).

As entrevistas-narrativas com os sertanejos, a partir desses temas ou de outros lembrados por eles, foram produzidas em suas próprias casas, após comentários sobre o objetivo da conversa e obtenção do livre consentimento em participar, garantindo os aspectos éticos da pesquisa. Para Street (2010, p. 41), ao tratar das práticas etnográficas em torno do letramento, deve-se, em vez de falar sobre algo que eles não têm, dizer sobre "o que eles têm", afastando-se da premissa de que todos vivem em uma mesma cultura, com os mesmos significados e linguagem. Street (2010, p. 46) lembra que um investigador pode 
estar "[...] indo rápido demais com seu entrevistado, quando faz uma pergunta direta como 'Que dificuldades encontraram como consequência de não saber ler e escrever?'”. Determinadas questões podem envolver relações mais amplas, de identidade, poder e significados sociais. Nesse sentido, procurou-se evitar, por exemplo, conversar diretamente com os sertanejos sobre o acesso a livros, mas sim sobre materiais de leitura a que eles tiveram contato; também se procurou evitar conversar, pelo menos de início, sobre a frequência à escola, já que os indícios são de que as escolas eram raras na região, mas sim sobre as práticas de escrita, sobre os processos que possibilitaram uma apropriação do código escrito. As práticas convencionais de aprendizagem podem dar lugar a diferentes situações de letramento, e são a essas situações que também se pretendeu produzir visibilidades com as entrevistas-narrativas.

Ao manter o foco na arte da escuta (PORTELLI, 2016), também foram inspiração para este trabalho as produções do cineasta brasileiro Eduardo Coutinho, principalmente o seu documentário O fim e o princípio, gravado em comunidades rurais do Nordeste, em 2005. Nesta produção, o diretor ouve muito mais do que fala e não há uma produção prévia; é a voz que emerge do cotidiano, das pessoas comuns do sertão, atribuindo autoria e protagonismo ao processo de produção.

Assumiu-se a postura de não atribuir julgamentos de valor no que se refere à veracidade das narrativas, considerando-se que não existe voz pura, porque é sempre determinada por um sistema, como o social ou o familiar, e codificada por uma recepção, conforme Certeau (2013). Se a memória é construída de acordo com as redes de poder, com as relações desenvolvidas em experiências passadas, vividas em interação com diferentes grupos, foi preciso valorizar as lembranças, as escolhas realizadas por cada pessoa durante as narrativas, em que a memória individual emerge de uma memória coletiva. 
Segundo Portelli (1991), essa subjetividade do expositor é um precioso elemento das fontes orais e que nenhuma outra fonte possui em medida igual.

Em relação ao processo de gravação, manteve-se um ambiente informal nas casas, sem utilizar grande aparato tecnológico, e isso pode não ter garantido a qualidade técnica dos vídeos/áudios, mas favoreceu narrativas mais espontâneas e livres. As condições acústicas e de iluminação não foram ideais, havendo interrupções por causa da chegada de outras pessoas, barulho de animais, automóveis etc.; em alguns trechos das falas, a emoção ou a dificuldade de "lembrar" pode ter contribuído para um tom de voz muito baixo e/ou ininteligível, o que dificultou o trabalho posterior de audição e transcrição.

A transcrição das entrevistas-narrativas não foi realizada de modo integral, pois foram escolhidos, principalmente, os trechos que abordam os temas relacionados às práticas de escrita e leitura, foco deste estudo ${ }^{9}$. Os diálogos envolveram temas que não faziam parte do planejamento da entrevista, como as dificuldades da vida na roça, a rotina do trabalho, a vida de outros familiares etc. No caso de alguns entrevistados que demonstraram certa introspecção, com dificuldade para desencadear o fluxo da narrativa, foi necessária a realização de mais intervenções, por parte da pesquisadora.

Realizou-se uma transcrição grafemática, na tentativa de tornar a leitura acessível ao pesquisador, mas há elementos (expressões, entoação etc.) que são próprios ao texto oral, difíceis de serem apresentados em uma transcrição. Os sinais de pontuação inseridos, a fim de tornar a transcrição legível, quase nunca coincidem com os ritmos e pausas do sujeito falante, de acordo com Portelli (1991). E a duração das pausas, a mudança de ritmo na narrativa, são elementos importantes no discurso. A recorrência às gravações é necessária, portanto, para

\footnotetext{
9 Os trechos das narrativas transcritos são apresentados em Santiago (2019). A maior parte da transcrição, com nossa revisão, foi realizada pela pesquisadora Me. Rosana Brito, integrante da equipe do projeto CE-DOHS, da UEFS.
} 
os que pretenderem desenvolver estudos a partir dessas entrevistas-narrativas, sobretudo para a realização de pesquisas linguísticas.

Foram realizadas 12 entrevistas-narrativas (com 10 remetentes e 2 destinatários das cartas). Dos redatores e destinatários que estão vivos, foram priorizados, na escolha dos que seriam entrevistados, os mais velhos e os que possuem uma quantidade significativa de cartas enviadas ou recebidas. As gravações, registradas em vídeos, têm duração, em média, entre 15 e 30 minutos. Esse acervo de entrevistas-narrativas, junto ao conjunto de manuscritos, contribui para a garantia da preservação da memória dos sertanejos, reconhecendo-se a necessidade de que sejam produzidas visibilidades, de ouvir aqueles que, ao longo do tempo, estiveram às margens das atividades de escrita, ofuscados pela história oficial, vistos agora como agentes de suas histórias de vida, disponibilizando-se fontes de especial raridade para os estudos linguísticos, da História Social da Cultura Escrita, e inclusive para atender a interesses de outras áreas do conhecimento.

\section{AS PRÁTICAS DE LETRAMENTO EM ESPAÇOS ESCOLARES E NÃO ESCOLARES NO SERTÃO BAIANO}

Nas narrativas, os sertanejos expressam sobre seu passado na roça, sobre como criaram, com as possibilidades cotidianas, maneiras de apropriação e de produção das práticas de escrita. Sobre esse papel ocupado pelos sujeitos na produção da cultura escrita, Galvão (2010, p. 219, grifos da autora) comenta ser “[...] pouco fértil, do ponto de vista da pesquisa, afirmar que os indivíduos e/ou sociedades entram e se inserem na cultura escrita ou têm acesso a ela". Pode-se, no limite, usar essas expressões em referência à cultura legitimada politicamente como superior, afinal, segundo a autora, os seres humanos "[...] produzem cotidianamente bens materiais e simbólicos em várias dimensões de sua vida, consequentemente também em relação ao escrito". 
Através das memórias, nota-se o desejo que nutriam de aprender a escrever: "eu ficava só olhando, observano, né? Observano eles leno aquilo ali e eu ficava naquela vontade $[. . .]^{\prime \prime}(\mathrm{AFS})^{10} \mathrm{e}$ "olha eu tinha vontade de... de aprender a ler, era uma vontade grande [...]" (IZA). Em várias falas, esse envolvimento emocional com a aprendizagem da leitura e da escrita é percebido, como nesse trecho, em que a narradora descreve a emoção dos pais com a aprendizagem dos filhos:

[...] quando a gente pegou a... a fazer o nome da gente, o nome de pai, de mãe, dos irmão de dento de casa todo né... aí tinha dia que a gente pegava fazia, pai chorava mais mãe... porque diz que a gente já tava sabeno o que eles num sabia né... porque naquele tempo era tudo assim atrasado. (ASC)

A necessidade de escrever, muitas vezes, é motivada pelo próprio prazer que sentem com a prática da escrita, como sugerem os trechos das narrativas. Uma das narradoras deixa explícita a emoção que sobressai desse desejo de escrever cartas: “Gostava... era o que mais eu gostava... quando dizia assim, vou escrever pra uma amiga, pra mim era meu sonho, sem saber... toda doida que não escrevia direito... mas mesmo assim... eu tinha o prazer de dizer... eu falar com eles por carta era meu sonho" (NIN).

Como, para muitos, não era possível ir à escola regularmente, esse desejo contribuiu para que inventassem, em seu cotidiano, maneiras de fazer, não se conformando a sua realidade. São as táticas usadas para se apropriar de uma prática que é considerada por Certeau (2013, p. 206) como responsável pela iniciação na sociedade dos últimos três séculos, já que “[...] aprender a escrever define a iniciação por excelência em uma sociedade capitalista e conquistadora. É a sua prática iniciática fundamental". Prática a que muitos dos sertanejos não

10 A identificação das entrevistas é realizada com a indicação, nos parênteses, da mesma sigla usada para se referir aos redatores das cartas em Santiago (2019). 
tiveram acesso quando criança, mas que tentam recuperar na fase adulta, pela necessidade que sentem, de participação no mundo letrado.

Foi possível recuperar informações sobre o processo de aquisição da escrita de 39 dos 53 redatores das Cartas em Sisal. Além das entrevistas-narrativas produzidas com 12 deles, algumas conversas com os familiares possibilitaram obter indícios de como aprenderam a escrever, ainda que não tenha sido possível o contato com alguns (porque já são falecidos ou porque não foi possível encontrar a residência atual): 25 sertanejos desenvolveram a aprendizagem da escrita em casa; quatro estudaram apenas os primeiros anos; oito estudaram até a quarta série; uma estudou até a quinta série, e um declara ter aprendido por meio da convivência com os amigos, que sabiam escrever, e do contato com textos religiosos.

Correlacionando-se esses percursos de participação na cultura escrita ao desempenho na técnica de escrever de alguns redatores, verifica-se que não há muita diferença de habilidade entre aqueles que frequentaram mais tempo um espaço escolar e os que não tiveram essa oportunidade. A partir do estudo de alguns aspectos das Cartas em Sisal (cf. SANTIAGO, 2019), estabeleceu-se uma gradiência, um contínuo de inabilidade em escrita a partir do grau de desconhecimento do padrão gráfico e das características caligráficas manifestadas nos textos, em que o nível máximo é identificável pela incidência do maior conjunto possível de aspectos (principalmente o desconhecimento do padrão gráfico, como a dificuldade em grafar sílabas complexas), enquanto que os níveis parcial e mínimo são caracterizados pela incidência menor desses aspectos. No quadro a seguir, há uma distribuição dos remetentes das cartas, com a correlação entre o processo de aprendizagem da escrita e a sua caracterização quanto ao nível de inabilidade com a escrita: 
Quadro 1: Distribuição dos remetentes das cartas de acordo com o meio de aprendizagem da escrita

\begin{tabular}{|c|c|c|c|c|c|c|c|c|}
\hline \multirow{2}{*}{$\begin{array}{c}\text { Remetentes } \\
\text { das cartas } \\
\text { pessoais }\end{array}$} & \multicolumn{5}{|c|}{ Processo de aprendizagem da escrita } & \multicolumn{3}{|c|}{$\begin{array}{l}\text { Caracterização no } \\
\text { contínuo de } \\
\text { inabilidade em escrita } \\
\text { alfabética (Santiago, } \\
\text { 2019) }\end{array}$} \\
\hline & $\begin{array}{l}\text { Convivência } \\
\text { com amigos } \\
\text { e contato } \\
\text { com escrita }\end{array}$ & $\begin{array}{l}\text { Estudou } \\
\text { pouco } \\
\text { em casa }\end{array}$ & $\begin{array}{l}\text { Estudou } \\
\text { os } \\
\text { primeiros } \\
\text { anos }\end{array}$ & $\begin{array}{l}\text { Estudou } \\
\text { até a } \\
\text { quarta } \\
\text { série }\end{array}$ & $\begin{array}{l}\text { Estudou } \\
\text { até a } \\
\text { quinta } \\
\text { série }\end{array}$ & 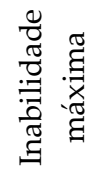 & 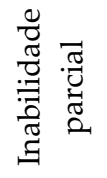 & 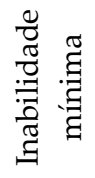 \\
\hline AFS & + & & & & & + & & \\
\hline $\mathrm{AO}$ & & + & & & & + & & \\
\hline APS & & + & & & & & + & \\
\hline $\mathrm{AOL}$ & & + & & & & + & & \\
\hline $\mathrm{ACO}$ & & + & & & & & + & \\
\hline $\mathrm{APC}$ & & + & & & & & & + \\
\hline DCS & & + & & & & + & & \\
\hline FJO & & + & & & & & & + \\
\hline FPS & & + & & & & & + & \\
\hline $\mathrm{FP}$ & & + & & & & & + & \\
\hline GOR & & + & & & & & + & \\
\hline IC & & + & & & & & + & \\
\hline ICO & & + & & & & & + & \\
\hline IZA & & + & & & & & + & \\
\hline JOM & & + & & & & & & + \\
\hline $\mathrm{JCO}$ & & + & & & & & + & \\
\hline $\mathrm{JPC}$ & & + & & & & & + & \\
\hline JS & & + & & & & + & . & \\
\hline $\mathrm{JJO}$ & & + & & & & & + & \\
\hline ZJS & & + & & & & & & + \\
\hline LFO & & + & & & & & + & \\
\hline $\mathrm{MCO}$ & & + & & & & & + & \\
\hline $\mathrm{MC}$ & & + & & & & + & & \\
\hline ROM & & + & & & & & + & \\
\hline $\mathrm{RCO}$ & & + & & & & & & + \\
\hline SFS & & + & & & & & + & \\
\hline JMA & & & + & & & + & & \\
\hline ZLS & & & + & & & & + & \\
\hline $\mathrm{DCO}$ & & & + & & & & + & \\
\hline ZSS & & & + & & & & + & \\
\hline $\mathrm{AHC}$ & & & & + & & & + & \\
\hline ASC & & & & + & & & + & \\
\hline $\mathrm{BMO}$ & & & & + & & & + & \\
\hline NIN & & & & + & & & + & \\
\hline $\mathrm{MMO}$ & & & & + & & & + & \\
\hline VAN & & & & + & & + & & \\
\hline RAC & & & & + & & & + & \\
\hline TB & & & & + & & & + & \\
\hline $\mathrm{ZBO}$ & & & & & + & & + & \\
\hline
\end{tabular}

Fonte: elaboração própria. 
Considerando-se a habilidade com a escrita, não há muita diferença entre aqueles que não frequentaram uma instituição formal de ensino e os que estudaram os primeiros anos, ou seja, todos os remetentes das cartas, independente de como tiveram acesso às primeiras letras, apresentam, nos seus produtos gráficos, aspectos próprios a adultos estacionados em fase inicial de aquisição da escrita.

Figura 1: Fac-símile da carta 38 (NIN), do acervo Cartas em Sisal

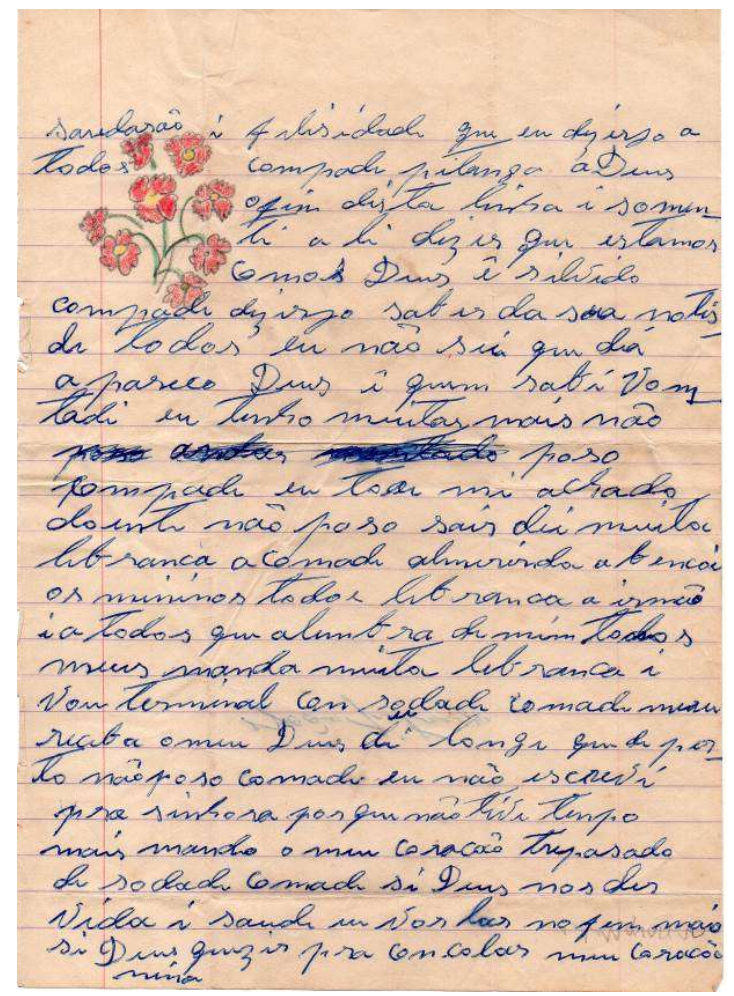

Fonte: Santiago (2019, p. 460).

E os narradores demonstram consciência dessa pouca habilidade com a escrita. Um deles se refere à própria caligrafia, caracterizando-a como "garranchos", termo que comumente é atribuído a letras pouco legíveis, em uma alusão a gravetos, a galhos finos e contorcidos de árvores: “tinha vez de escrever dez carta pra Bahia... aqueles garrancho, aquelas cartinha...", e lembra que "aí fazia aquela letra toda garranchada... [...] fazia aquelas carta toda doidada, esgarranchada, sem saber o quê... (rindo)" (AFS). 
De acordo com Galvão (2001, p. 81), por vezes, “[...] tem-se a impressão de que, entre as camadas analfabetas ou semi-alfabetizadas, a única mediação entre a leitura e a escrita é realizada pela escola", mas a autora complementa, afirmando que "[...] práticas educativas têm ocorrido, ao longo do tempo, fora da escola e, às vezes, com maior força do que se considera, principalmente para determinados grupos sociais e em determinadas épocas". E, nas narrativas, foram identificados alguns elementos que podem ter favorecido a aproximação e a participação desses sujeitos na cultura escrita, além da experiência escolar: o ambiente doméstico, o processo de migração, as práticas religiosas, o acesso a materiais impressos e a manuscritos foram fundamentais. A seguir, comenta-se sobre a presença desses elementos, a partir das narrativas.

\subsection{O espaço doméstico}

A própria casa, a de parentes ou a de alguma professora serviu, muitas vezes, como espaço de aprendizagem, seja através da intermediação dos pais, de outros membros da família ou mesmo de uma professora. Em algumas narrativas, é bastante mencionada a contribuição dos pais na aprendizagem, ainda que fiquem explícitas as limitações que existiam, pois os pais estudaram pouco ou eram analfabetos: “[...] esse tantinho que eu tenho... que eu sei... foi aprendido aqui porque papai ensina boca de noite com aquela letra grande... depois xixilô..." e também diz que "mamãe ensinou o ABC que ela sabia... ela sabia um pinguim de nada (rindo) meu pai também... [...] ele não dava muito valor a mulher aprender" (ZJS).

Três dos narradores são de uma mesma família - a mãe, um filho e uma filha. E, nas falas dos três, a "casa" é mencionada como o lugar de aquisição da escrita. A mãe, que aprendeu com a irmã, depois, ensinou aos filhos: “Ah, eu aprendi dento de casa com a minha irmã... foi aí eu... só... pratiquei o pouco que 
aprendi, ficava leno livro, letra graúda ne jorná, até que... aprendi fazer [...] É, eu ensinava meus fi dento de casa... foi... todos ele eu ensinava que não tinha escola aí eu ensinava aí..." (AMO). Os filhos lembram-se desses momentos:

Ah... com muito trabalho, eu ia pa roça, quando era mei dia mãe dava... que eu num tive ne escola, eu aprendi com mãe... mãe dava era... era lição... chamava lição, enquanto num desse... enquanto num desse num... num ia pra roça... [...] a escola daqui só era mãe que ensinava a da gente. (ACO).

Mãe é que dento de casa... mãe tinha livro... comprou um $A B C$, eu lembro como hoje, comprou um $\mathrm{ABC}$ que naquele tempo também quase que eles não saía... mas ele comprou... ela comprou... ensinava a gente dentro de casa... meus irmão tudo. (DCO)

Um dos narradores do município de Riachão do Jacuípe, que não vivenciou esses espaços domésticos, porque seus pais eram analfabetos, e que também não frequentou escolas, ao lembrar-se da presença temporária de uma professora na região, descreve o espaço em que as aulas, onde suas irmãs “aprendeu pouquinho assinar o nome", aconteciam: "e essa mulé veio, ensinou poucos dia [...] Era uma casa... a casa de meu avô... era a casa de meu avô, ensinava assim, numa salinha assim, como essa assim, era na roça" (AFS). A seguir, uma descrição semelhante, em que as casas dos familiares foram usadas por uma professora para as aulas:

É uma casa (rindo). Primeiro começou na casa de tio Gidásio... depois passou pra casa de meu irmão, aí ela casou e... começou... ela saiu e depois voltou, aí ela fez a casa dela aí ela ensinava lá na casa dela... a gente inda estudou uns dois anos ainda na casa dela... e daí eu... chegou o tempo de... de eu me casar... aí eu também... eu num estudei mais. (DCO)

Esses trechos evidenciam que, muitas vezes, o espaço doméstico confundia-se com o escolar. Ao comentar que estudou pouco tempo em uma escolinha e ao ser questionada sobre como era o espaço, a narradora diz que "era em casa, era na casa da... da mulher, da dona da casa mesmo..." (ZSS). Então, na ausência de um espaço específico para o funcionamento da escola, a "casa" (de 
algum morador do lugar ou da própria professora) era usada para as aulas, quando alguém da região resolvia ministrar aulas de primeiras letras ou quando aparecia alguma professora vinda de outros lugares e que permanecia, às vezes, por alguns meses apenas.

\subsection{O processo de migração}

A necessidade de manter comunicação com os familiares e amigos que ficaram no sertão motivou os sertanejos, que viajaram para as grandes cidades em busca de trabalho, a produzirem cartas, de modo que 32 (17 com indicação de local e 15 por inferência), das correspondências que constituem o acervo Cartas do Sisal, foram emitidas, principalmente entre as décadas de 1950, 1960 e 1970, de São Paulo, centro industrial da época, e uma de Brasília, durante a construção dessa cidade ${ }^{11}$.

Nesse sentido, o processo de migração também colaborou para a aprendizagem da escrita. Principalmente nesse período, expressivos movimentos de migração interna ocorreram no país, tendo como principal origem a região Nordeste, em consequência tanto do crescimento industrial, nas grandes cidades, quanto das dificuldades com o trabalho agrícola, devido aos longos períodos de seca, frequentes no semiárido baiano. A distância dos familiares e amigos que ficaram na terra natal foi, então, decisiva para que, mesmo sem muito domínio da técnica, enviassem cartas escritas a próprio punho, como é possível perceber nesta narrativa:

E aí eu escrevi ne São Paulo ne cinquenta e... essas carta aí que eu fiz foi de cinquenta e oito... escrevi pra Bahia... lembrava dos amigos tinha sodade dos amigo... muita sodade... aí os os cara que tinha carta escrevida... olhava

11 As já conhecidas dificuldades, próprias a esse processo migratório vivido pelos nordestinos, são expressas em um trecho da carta enviada de Brasília para a zona rural de Riachão do Jacuípe, em 1959: "[...] Compadre diga a Juão nasimento | que brazilha e iluzão i so vem quem nãol sabe" (GOR-Carta 29). 
olhava [inint.] ia fazeno... eles ia me ensinano, e aí escrevia quato, cinco... oito... dez... tinha vez de escrever dez carta pra Bahia... [...]. (AFS)

A experiência urbana, de modo geral, a convivência com amigos que escreviam cartas, usadas como "modelos", o contato com outros materiais escritos, a exemplo de um jornal da época, A Gazeta, lembrado por um dos narradores, contribuíram para o desenvolvimento da prática de escrever cartas: “essas carta eu fiz de lá [...] eu via as carta dos outros, eu pegava as carta... olhava pras carta assim e escrevia essas... se eu lhe dizer que eu já tive um dia de escola to lhe contando falso... nunca tive um dia" (AFS).

\subsection{O acesso a materiais impressos e manuscritos}

De acordo com Galvão (2010), muitas vezes, são os objetos de leitura menos consagrados pelos cânones literários, pela cultura legitimada, aqueles que mais contribuem para a aproximação da cultura escrita de grande parte da população brasileira.

No caso dos sertanejos, o contato com alguns materiais de leitura, como os textos religiosos, os folhetos de cordel e as cartas de outras pessoas, pode ter contribuído significativamente para a sua participação na cultura letrada. Os textos religiosos são fortes motivadores, como para o narrador do trecho a seguir, que não frequentou os espaços de aprendizagem, mas explica a própria aquisição da escrita pela ação divina: “[...] que na Bibla diz, Salomão foi o rei mais sábio que existiu na face da terra [...] aí eu fiquei nesta aí e leno aquelas passage... procurano ler pra entender e eu sei que... foi por Deus mehmo que abriu a minha mente e colocou quilo ali" (AFS).

Para os que estudaram com uma professora - alguns, apenas poucos meses -, a presença desses escassos materiais de leitura é algo a mais, como para essas duas narradoras: “Assim... eu leio um... como bem... o livrinho que retira o 
folheto da... que vem da igreja" (ASC) e "As vez eu pego uma revista de Nossa Senhora Aparecida aí sento ali no banco e olho, de letra mais graúda" (NIN). A presença de elementos de caráter religioso, nas memórias, é recorrente, associados a contextos de leitura: “Eu leio a Bíblia, leio folheto, eu leio livro religioso e leio arguma bobage que aparecer de... de qualquer coisa que eu ver escrito quero ver o que tem dento" (AMO).

Figura 2: Folhas de calendário religioso, presentes na casa dos sertanejos

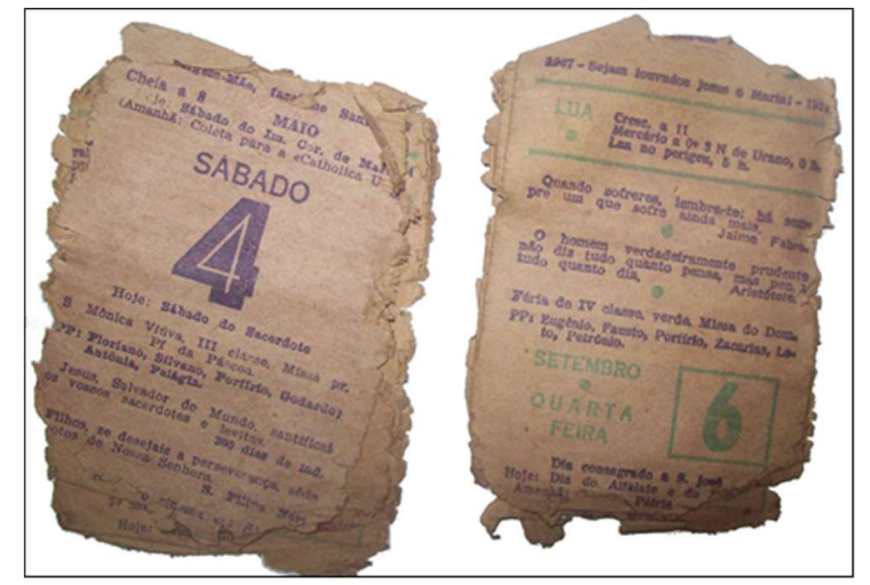

Fonte: acervo pessoal de José Messias, sertanejo da região.

Além disso, alguns sertanejos tiveram contato com os folhetos de cordel, conhecidos como "ABC de poesia": "Neso botou uns abc, daqueles abc de poesia den-... numa caxinha assim de papelão, botou meu livro junto, quando deu fé o rato tinha (bombado)... roeu um bocado de página do meu... do meu livro" (ASC). Em uma das casas onde as entrevistas-narrativas foram produzidas, foi encontrado um acervo constituído por vários exemplares desses cordéis. Galvão (2007, p. 41) comenta, ao tratar de situações em que a entrada na escrita é mediada por uma aproximação entre oralidade e escrita, tornando-a mais natural, menos marcada por tensões, que na leitura coletiva de cordéis, há essa relação entre oral e escrito, “[...] facilitando a participação na cultura escrita daqueles que não sabem ler nem escrever, na medida em que o cordel é um gênero escrito com profundas marcas da oralidade". A autora lembra, a partir de um estudo anterior, 
que, nas décadas de 1930 e 1940, em Pernambuco, principalmente na zona rural, a leitura de cordéis em voz alta era bastante valorizada, e aqueles que detinham essa competência exerciam poder sobre os demais; por outro lado, “[...] principalmente os que viviam na zona rural, não tinham a dimensão de que aquele domínio da leitura e da escrita era pouco valorizado em outras práticas de letramento, principalmente urbanas" (GALVÃO, 2007, p. 38).

Essa necessidade da leitura em voz alta dos folhetos de cordel também esteve presente durante a gravação das entrevistas-narrativas, na casa de um casal onde um conjunto desses folhetos, das décadas de 1950, 1960 e 1970, foi encontrado. Entre uma conversa e outra, o marido da narradora fez questão de ler vários deles, demonstrando o domínio da leitura e o valor afetivo-emocional dado às histórias: "Foi quem mais cresceu minha leitura foi livro de história, [...] eu tenho oh (rindo)... eu tenho um feche assim de livro assim de cordel... de muitos tempo, muitos ano, mas tem livro bonito... tem livro bonito... tem livro que o cara lê corre água dos olho" (marido de ZSS). Nos folhetos, há indícios de que foram manuseados por várias pessoas da região, parentes e amigos do dono do acervo, pela presença de assinaturas e outros escritos (inclusive, em um deles, há a assinatura de AFS, um dos narradores/remetentes das cartas):

Figura 3: Folheto de cordel, presente no sertão baiano (meados do século XX)
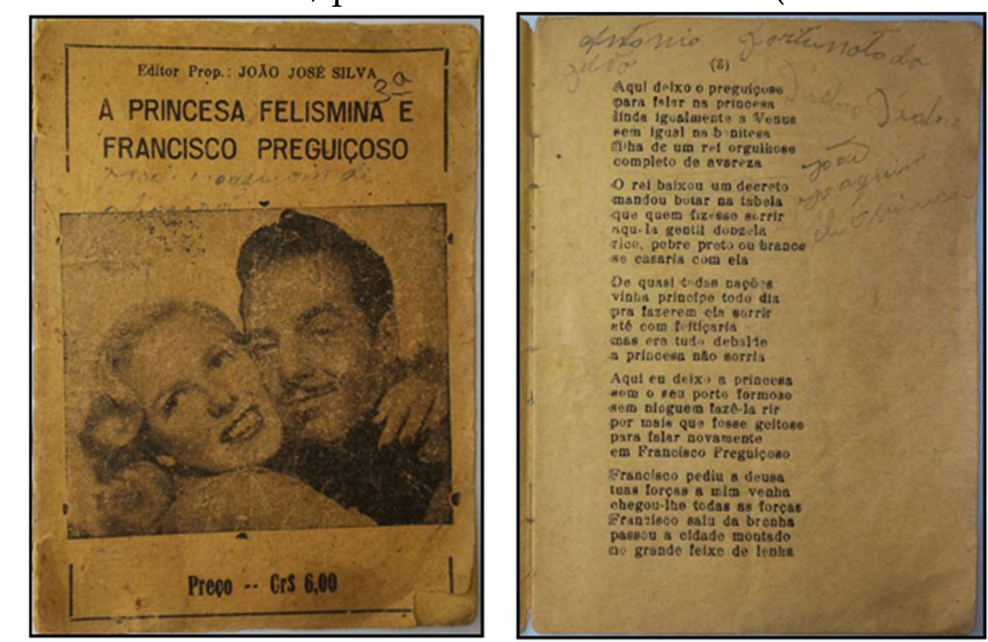

Fonte: acervo pessoal do casal Antonio Carneiro e Zulmira Sampaio. 
Constata-se, então, que esses cordéis chegaram até a região, comprados, segundo o dono do acervo, nos dias de feira, em Conceição do Coité ou em Riachão do Jacuípe; e, seja através da leitura ou da audição da leitura, esses textos contribuíram para o processo de difusão da cultura escrita na região.

Outro tipo de material impresso mencionado nas falas de alguns é o texto jornalístico, que fez parte dos processos de letramento, mesmo que de forma limitada, como é expresso em uma das narrativas: “As veze, minha filha, vinha jornaus velho antigo, embrulhando alguma coisa, as veze com tecido, alguma coisa que vinha... aí a gente aproveitava queles jorná pra ler, a gente lia muito, falar a verdade, eu mesmo, eu e compadre José, compadre José gostava [...]" (IZA). Nas memórias da vida em São Paulo, também aparece a imagem do jornal: “[...] aqueles cara que... que sabia ler ficava leno pegava aquelas gazeta, aqueles papel ia leno, eu ficava só olhando, observano, né? Observano eles leno aquilo ali e eu ficava naquela vontade" (AFS). Os amigos que liam A Gazeta, como já comentado, também escreviam cartas, e esse contato com os manuscritos produzidos pelos companheiros, para os que estavam morando longe de casa, ajudou a uma melhor familiarização com a escrita.

Sobre livros didáticos, as cartilhas (também chamadas de $A B C$ ) são mencionadas em algumas narrativas; no entanto, não foi possível recuperar lembranças muito precisas sobre os detalhes dessas cartilhas, como títulos, autores etc.

Mas só que num tinha condições nem de comprar os livro... aí ela [a mãe] comprou, lembro como hoje, que ela comprou três cartilha... chamava Paulinho, essas cartilha um pra mim, uma pra minha irmã, uma pro meu irmão, a gente ia pra Jiboia, dá mais ou menos uns... [...] uns quatro quilômetro daqui pá lá, mas a gente ia todo dia [...] Ia de pé... nós ia andano de pé... [...] e aí eu estudei trinta dias a gente... eu e meus irmão estudemo trinta dias, mas era com siedade de aprender. (IZA)

Os livros também foram lembrados por uma das narradoras, a mais jovem, nascida em 1966, ao falar da presença de romances em sua casa: “eu... tinha 
romance, logo a gente começou, ficou, tinha muitos romance e eu tentava, eu lia muito romances, né? Num tinha televisão na época, era romance mesmo e livros" (LCC). O único livro didático encontrado nos acervos pessoais, que foi conservado pelo filho de um dos casais redatores das cartas (JMA e AHC), é o que tem algumas páginas representadas na Figura 4, provavelmente utilizado entre as décadas de 1960 e 1970. Como não apresenta capa e nem contracapa, não foram identificadas informações sobre título, autor e editora.

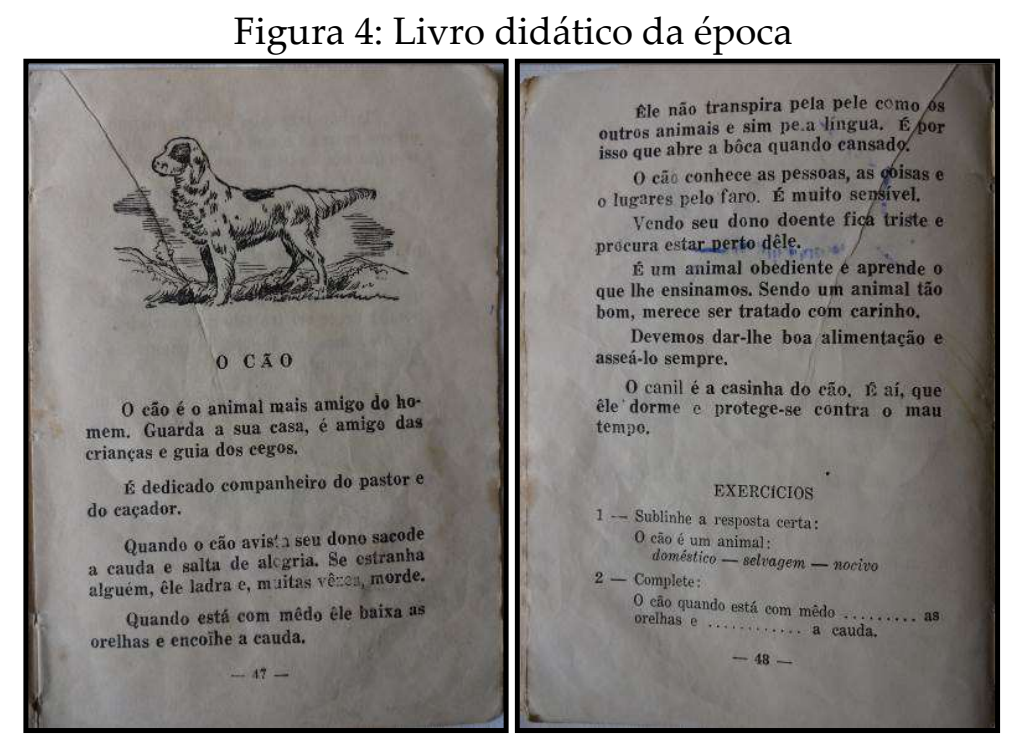

Fonte: acervo pessoal de Ana Helena Cordeiro.

\subsection{A experiência escolar}

A existência de um espaço escolar é sempre associada, nas narrativas dos sertanejos que frequentaram de algum modo esse espaço, à dificuldade de acesso, geralmente por causa da distância geográfica e/ou pelas baixas condições financeiras, como ilustrado neste trecho da fala de um dos narradores, de Riachão do Jacuípe:

[...] pai era difíço botar um filho na escola, num tinha condições... pai não tinha condições nem pra comer nem pra sustentar um filho [inint] botar ne escola... e quando existia uma escola era bem longe só botava quem tinha dinheiro... as criança ia montado de animal, nós não... (AFS) 
Essa narrativa reflete a afirmação de Rios (2015), de que a educação oferecida aos sujeitos que moram em áreas rurais, durante um longo período da história da educação no Brasil, sempre foi silenciada e relegada a segundo plano. No início do século $X X$, segundo essa autora, a inserção da educação rural nos textos constitucionais surge apenas em 1930, com o “[...] objetivo fundante de apaziguar as tensões sociais decorrentes do êxodo rural, estando a serviço dos interesses políticos e econômicos da época" (RIOS, 2015, p. 25).

A dificuldade de acesso à escola também fica evidente na fala de uma das narradoras, de Conceição de Coité, nascida em 1936. Após ter mencionado sua ida à escola, explica onde ela era localizada e lembra-se das dificuldades:

Ah, minha fia, era longe... era como daqui na Barra... a gente ia de pé, os camim dentro numas Catinga, passava duas turma de animal carregado, de manhã e de tarde, e a gente ia tudo com as percatinha na mão e a lama atolano [inint] quando chegava na... era Deus que na chegada da escola tinha um tanque... aí agora a gente lavava os pé pra cabar de chegar. (ASC)

Na maioria das vezes que esse espaço foi mencionado, a descrição física é associada ao ambiente doméstico, como já foi comentado; e, nas falas, percebe-se a imagem do que era considerada uma escola naquela época, no meio rural, em que se inventavam espaços de ensino-aprendizagem. Na maioria das descrições, é a casa da própria professora que serve como espaço escolar:

[...] a escola era na residência dela... lembro, num quartinho na residência mesmo na frente, aí ela ensinava... ensinava a gente... ensinava um grupo lado de lá de Cansanção, lá da Jiboia, do pessoal deles lá, viu? E de Riachão acho que só tinha a gente mesmo... mas era a siedade que a gente tinha... a gente estudou trinta dias lembro. (IZA)

[...] Era na residência da professora Netinha... [...] Aí ela ensinava, tinha duas sala, tinha uma que era na frente, como o povo chamava... varanda, e no fundo tinha uma sala grande, aí quando o menino... os menino vinha muito, num era todo dia que vinha todo mundo, aí ela ensinava na sala que era maior e era mais fresca, tinha aqueles banco, a gente sentava e ensinava aí estudei até....a terceira série. (ZBO) 
A informalidade que caracterizava esses espaços escolares pode ser notada, por exemplo, na maneira como eram nomeados: “o nome da escola, era o mesmo nome que era o nome dela [da professora] que era... aqueles pessoal quando, antigamente, quando vinha uma professora aquele nome que a prof... que a professora viesse, aquele nome ficava dano a gente nos caderno [...]" (ASC). Também há descrições que coincidem, em relação à disposição dos móveis, em que os bancos substituíam as cadeiras: "Tinha banco (rindo) esse tempo era uns baquin-... o povo tinha uns banquinho a mesa com uns banco... de primeiro era tudo pobre num tinha nem cadeira (rindo) era difícil não era?" (ZSS) e "[...] não tinha cadeira não, botava os banco aí, sentava, cada um... não existia cadeira nesse tempo não (rindo)" (NIN).

A rara presença de professores, quase sempre itinerantes, na região, é explicada pela ausência de políticas públicas, nesse período, voltadas para a educação no campo. No século XX, a partir de 1934, surgem as primeiras escolas normais rurais, no Nordeste (no Ceará, em 1934; em Feira de Santana, na Bahia, em 1935), com o objetivo de formar professores da zona rural; no entanto, muitos locais, como o interior da Bahia, “[...] não contavam com docentes formados(as) em escola normal, prevalecendo, por várias décadas do século $X X$, a forte presença de docentes leigos(as) nestas escolas rurais" (RIOS, 2015, p. 27). Poucos professores formados na Escola Normal Rural atuavam na zona rural, pois preferiam trabalhar nas cidades.

Por causa dessa raridade de professores, duas das narradoras comentam que, mesmo com pouco estudo, tiveram que ministrar aulas; uma para substituir a professora, quando se ausentava, e a outra pelo desejo de ver os jovens aprenderem, pelo menos, a assinar o nome:

[...] aí eu estudei, estudava e ensinava ao mesmo tempo, que ela fazia curso, aí eu ficava no lugar dela pra ensinar assim os menino do primeiro ano, do pré, era pré... pré até o segundo... aí eu já ensinava, ela dizia “Olha [inint] 
aqui tem o dever aqui tu passa tu mesmo se eles não acertar tu ensina eles". (ZBO)

Não... não estudei, mas... mas eu... quando eu vim pra qui, minha fia, num... cada um rapaz, cada uma moça assim [...] esses menino de vinte ano, vinte e um ano, num sabia fazer um nome, num conhecia letra [...] tudo assim pior do que eu... aí eu inventei de botar uma escolinha... aí "vocês quer aprender um pouquinho assinar o nome de vocês? Muito não, mas com nada aprender a fazer o nome de vocês" [inint] ah... foi menino, foi muito menino, era dezenove aluno. (NIN)

Ainda sobre a presença de professores na região, um dos narradores comenta que suas irmãs foram as únicas pessoas de sua casa que chegaram a frequentar uma escola. Ele lembra que uma professora veio para ensinar poucos dias na casa do seu avô: "[...] ensinava assim numa salinha assim... como essa... assim... era na roça". A presença da professora foi bastante passageira, o que confirma a ideia da raridade desse espaço:

Essa escola, a mulé chamava quem? Dinamérica... tinha o apelido de Lua [...] ela num era daqui não [...] ensinou poucos dia na casa do meu avô... de Zé de Angerca... [...] as menina aprendero... negoço de poucos dias um mês... um mês e meio... e pouco [...] essa mulé, essa professora [inint] que era professora... quem trouxe foi um homem, chamava Antonho do Sobrado... ele era marchante de gado... aqui ne Riachão tinha... (AFS)

Esse mesmo narrador, que afirma não ter frequentado a escola, diferente de suas irmãs, justifica isso com a necessidade de ajudar o pai com o trabalho da roça: “eu é quem trabalhava com meu pai com doze treze ano... quatorze ano... quem trabalhava era eu pra sustentá a família" (AFS). Além disso, a distância e as dificuldades de acesso foram impedimentos, como é possível notar no trecho a seguir, em que expressa a relação entre o nível socioeconômico das pessoas e o acesso à escola:

[...] num tinha escola... num existia escola... existia escola, mas quem estudava naquele tempo? Filho de ó (faz um gesto com os dedos indicando quem tem muito dinheiro)... uma pessoa naquele tempo pa formar um filho, ter um médico... um filho formado, era burguês é... nem os... a certos a 
arguma...a arguas pessoa da roça... fazendeiro... que era fazendero... que tinha umas condiçãozinha... às vez tinha pena de gastar ou num gastava, ou num queria... (AFS)

Nesse trecho, ele afirma duas vezes que não existiam escolas na região, mas para reforçar sua raridade, as dificuldades que havia, ainda que possuíssem boas condições financeiras, ou seja, fossem fazendeiros. O narrador apresenta indícios do valor que era dado à escola, já que a falta de condições financeiras não era o único entrave, pois os fazendeiros podiam "ter pena de gastar" ou simplesmente, não queriam gastar com isso, até porque àquela época, a escola podia não ser tão necessária para suas vidas. A função das aulas, de acordo com a memória do narrador, tendo por base a experiência de suas irmãs, era "só assinar o nome... era só assinar o nome só, a leitura de minhas irmã foi essa, só de assinar o nome... aí... leiturinha pouca..."(AFS) ${ }^{12}$. Saber assinar era a principal necessidade, uma forma de inclusão. As irmãs desse narrador também escreveram algumas cartas e, em seus textos, é evidente a pouca familiaridade com o código escrito, como os demais redatores, são adultos estacionados em fase incipiente de aquisição da escrita.

\section{CONSIDERAÇÕES FINAIS}

Para a identificação de indícios sobre os processos de difusão da escrita no semiárido baiano, das práticas letradas da época, apostou-se na potencialidade do uso de fontes orais. A partir das memórias narradas, foi possível verificar que, principalmente até meados do século $X X$, o processo de escolarização formal não

12 Essa afirmação sobre o que se aprendia na escola encontra correspondência nas memórias que fazem parte do projeto Memórias do Rural, publicadas por Freixo e Teixeira (2011), um trabalho desenvolvido com velhos moradores de comunidades rurais da região sisaleira: Seu Zezé Primo comenta: "Fui pra escola... naquele tempo não tinha escola, só se fazia aprender a assinar o nome, e qualquer coisa aí... tinha uns veios que ensinavam, um pouco mais, mas já ia embora, acabava aquela escola... eu aprendi a ler e escrever, estudando lá, com esse pedaço de tempo" (FREIXO; TEIXEIRA, 2011, p. 117-118). 
foi um fator determinante para o desenvolvimento das práticas de escrita pelos sertanejos. Eles inventaram modos próprios, legítimos, de se apropriar do processo de escrita, com as possibilidades cotidianas: além do espaço escolar (muitas vezes, improvisado, com professoras leigas), também os espaços domésticos, o acesso a materiais de leitura e o processo de migração para grandes cidades propiciaram formas de participação nas práticas de letramento. Ainda que circulassem na região folhetos de cordel, cartas, textos religiosos, cartilhas e, de forma muito rara, jornais, o acesso a textos modelares do período foi limitado. Correlacionando o desempenho na técnica de escrever aos percursos de participação na cultura letrada, verifica-se que não há muita diferença entre aqueles que frequentaram mais tempo um espaço escolar e os que aprenderam a escrever através de outros processos.

A busca de sentidos no passado permite perceber que os narradores atribuem legitimidade a seus processos de letramento, a suas práticas de escrita, que são formas de resistência, pois mesmo com as dificuldades do contexto sociocultural da época, reconhecem o desejo e a necessidade que os motivou a uma participação efetiva na cultura escrita.

\section{REFERÊNCIAS}

BURKE, Peter. Abertura: a nova história, seu passado e seu futuro. In: BURKE, P. (org.). A escrita da história: novas perspectivas. Tradução de Magda Lopes. São Paulo: Editora da Universidade Estadual Paulista, 1992. p. 7-37.

CARNEIRO, Rita de Cássia Oliveira. História de vida e trajetória de professoras leigas no sertão da Bahia. In: VI Congresso Internacional de Pesquisa (Auto)Biográfica: modos de viver, narrar e guardar, 2014, Rio de Janeiro. Anais... Rio de Janeiro: BIOgraph, 2014.

CARNEIRO, Zenaide de O. N.; ALMEIDA, Norma L. F.; LACERDA, Mariana F. de O.; SANTIAGO, Huda da S. O sistema educacional no semiárido baiano oitocentista e notas sobre a escolarização no período republicano feirense e da região sisaleira. In: CASTILHO, A. T. (coord.). História do Português Brasileiro - v. 9. São Paulo: Contexto, 2020.

CASTILLO GÓMEZ, Antonio. Historia de la cultura escrita: ideas para el debate. Revista brasileira de história da educação, n. 5, p. 93-124, jan/jun. 2003. 
CERTEAU, Michel de. A invenção do cotidiano: 1. Artes de fazer. Tradução de Ephraim Ferreira Alves. Petrópolis, RJ: Vozes, 2013.

CHARTIER, Roger. A história ou a leitura do tempo. Belo Horizonte: Autêntica Editora, 2010.

CRUZ, Antonio Roberto Seixas da. Mestras para o sertão: criação e funcionamento da Escola Normal de Feira de Santana. In: SOUZA, I. C. J.; CRUZ, A. R. S.. Escolas Normais da Bahia: olhares e abordagens. Feira de Santana: UEFS Editora, 2012. p. 43-65.

FREIXO, Alessandra Alexandre; TEIXEIRA, Ana Maria Freitas. Entre as trilhas da memória: velhos da Terra do Sisal. Feira de Santana: UEFS Editora, 2011.

GALVÃO, Ana Maria de Oliveira. Processos de inserção de analfabetos e semialfabetizados no mundo da cultura escrita (1930-1950). Revista Brasileira de Educação, Rio de Janeiro, v. 16, p. 81-94, 2001. Disponível em: [https://www.scielo.br/pdf/rbedu/n16/n16a08]. Acesso em: 06 set. 2020.

GALVÃO, Ana Maria de Oliveira. Oralidade, memória e narrativa: elementos para a construção de uma história da cultura escrita. In: GALVÃO, A. M. de O. et al. (org.). História da cultura escrita: séculos XIX e XX. Belo Horizonte: Autêntica Editora, 2007. p. 946.

GALVÃO, Ana Maria de Oliveira. História das culturas do escrito: tendências e possibilidades de pesquisa. In: MARINHO, M.; CARVALHO, G. T. (org.). Cultura escrita e letramento. Belo Horizonte: Editora UFMG, 2010. p. 218-248.

O FIM e o princípio. Documentário. Direção: Eduardo Coutinho. Roteiro: Eduardo Coutinho e Jacques Cheuiche. Rio de Janeiro: Videofilmes, 2005. (110 min.), son., color.

PETRUCCI, Armando. La ciencia de la escritura: primera lección de paleografía. Buenos Aires: Fondo de Cultura Económica de Argentina, 2003.

PORTELLI, Alessandro. What makes oral history different. In: The death of Luigi Trastulli and other stories: form and meaning in oral history. Albany: State University of New York Press, 1991.

PORTELLI, Alessandro. História oral como arte da escuta. São Paulo: Letra e Voz, 2016.

RIOS, Jane Adriana V. Pacheco. Profissão docente na roça. Salvador: EDUFBA, 2015.

RODRIGUES, Heliana de Barros Conde. A história oral como intercessor: em favor de uma dessujeição metodológica. Estudos e pesquisas em Psicologia, UERJ, ano 10, n. 1, p. 190-203, 2010. Disponível em: [http://www.revispsi.uerj.br/v10n1/artigos/pdf/v10n1a13.pdf]. Acesso em: 12 dez. 2018.

SANTIAGO, Huda da S.; CARNEIRO, Zenaide de O. N., Fontes para uma sócio-história linguística do português popular: as cartas de mãos inábeis do sertão baiano. A Cor das Letras, v. 17, n. 1. Feira de Santana, p. 90-98, 2016. Disponível em: [http://periodicos.uefs.br/index.php/acordasletras/article/view/1463]. Acesso em: 06 set. 2020. 
SANTIAGO, Huda da S. A escrita por "mãos inábeis": uma proposta de caracterização. 2019. 722f. Tese (Doutorado em Língua e Cultura) - Instituto de Letras, Universidade Federal da Bahia, Salvador, 2019.

SANTIAGO, Huda da S.; LACERDA, Mariana F. de O.; CARNEIRO, Zenaide de O. N. A Filologia e a história das línguas: contribuições do Núcleo de Estudos de Língua Portuguesa da Universidade Estadual de Feira de Santana. Macabéa - Revista Eletrônica do NETLLI, Crato, v. 8., n. 2., p. 352-371, 2019. Disponível em: [http://periodicos.urca.br/ojs/index.php/MacREN/article/view/1952]. Acesso em: 23 set. 2020.

SHARPE, Jim. A História vista de baixo. In: BURKE, P. (org.). A escrita da história: novas perspectivas. Tradução de Magda Lopes. São Paulo: Editora da Universidade Estadual Paulista, 1992. p. 39-62.

SOARES, Magda. Letramento: um tema em três gêneros. Belo Horizonte: Autêntica Editora, 2006.

SOUZA, Elizeu Clementino de (org.). (Auto)biografias e documentação narrativa: redes de pesquisa e formação. Salvador: EDUFBA, 2015.

SOUZA, Ione Celeste Jesus de; CRUZ, Antonio Roberto Seixas da. Escolas Normais da Bahia: olhares e abordagens. Feira de Santana: UEFS Editora, 2012.

STREET, Brian V. Os novos estudos sobre o letramento: histórico e perspectivas. In: MARINHO, M.; CARVALHO, G. T. (org.). Cultura escrita e letramento. Belo Horizonte: Editora UFMG, 2010. p. 33-53.

STREET, Brian V. Letramentos sociais: abordagens críticas do letramento no desenvolvimento, na etnografia e na educação. Tradução de Marcos Bagno. São Paulo: Parábola Editorial, 2014.

WORCMAN, Karen. Narrativas digitais: eu, nós e quem mais? A relação entre histórias de vida e museus digitais. In: OSWALD, M. L. M. B.; JUNIOR, D. R. do C.; WORCMAN, K. (org.). Narrativas digitais, memórias e guarda. Curitiba, PR: Editora CRV, 2014. p. 145155.

\section{A AUTORA E O PPGLinC}

\section{Huda da Silva Santiago}

Graduada em Letras Vernáculas (2002) pela Universidade Estadual de Feira de Santana (UEFS), com especialização (2007) e mestrado em Estudos Linguísticos (2012) pela mesma instituição. O doutorado em Língua e Cultura, pelo Programa de Pós-Graduação em Língua e Cultura da Universidade Federal da Bahia (UFBA), em 2019, foi fundamental para a afirmação profissional na área: no último ano do curso, foi aprovada como Professora Assistente da UEFS, onde atua na graduação e na pós-graduação. A pesquisa desenvolvida no doutorado 
possibilitou a construção e atual coordenação do projeto Documentos produzidos por mãos inábeis: estudos linguísticos e filológicos, vinculado ao Corpus Eletrônico de Documentos Históricos do Sertão, da UEFS. É pós-doutoranda pelo Programa de Pós-Graduação em Letras Vernáculas, da Universidade Federal do Rio de Janeiro, sob supervisão do professor Afranio Barbosa, e integra o Projeto para a História do Português Brasileiro e o Programa para a História da Língua Portuguesa.

Nota do editor:

Artigo submetido para avaliação em: 26 de outubro de 2020.

Aprovado em sistema duplo cego em: 11 de março de 2021. 